\title{
CIUDADANOS, APÁTRIDAS, EXILIADOSY MIGRANTES: LA DIÁSPORA ECUATOGUINEANA DE LA COMUNIDAD DE MADRID
}

\author{
Raúl Sánchez Molina \\ Profesor UNED \\ ersanchez@fsof.uned.es
}

\section{Enrique Galiano Sierra e Inmaculada López}

Inspección SS Sanitarios Comunidad de Madrid

\begin{abstract}
Resumen: Condiciones histórico-estructurales vinculadas al colonialismo, la pervivencia de estructuras de poder heredadas del franquismo y los actuales procesos de globalización del capital son algunos de los factores que explican que Guinea Ecuatorial continúe siendo un país expulsor de refugiados y migrantes desde su independencia en 1968. Y que España, como antigua metrópoli colonial, sea el país receptor de gran parte de su diáspora. El origen y el desarrollo de ésta no hace más que incidir en la asociación que en los estudios migratorios y transnacionales se ha establecido entre condiciones estructurales tanto en países expulsores como receptores con los modos de incorporación de refugiados y migrantes en los lugares de asentamiento, con el desarrollo de redes sociales $y$ de relaciones transnacionales poscoloniales. A partir de investigaciones etnográficas llevadas a cabo con migrantes y refugiados ecuatoguineanos asentados en la región metropolitana de la Comunidad de Madrid, este artículo describe y analiza cómo estos factores afectan sus modos de incorporación y adaptación a esta región metropolitana, así como el mantenimiento de relaciones sociales y culturales con sus sociedades de origen.
\end{abstract}

Palabras Clave: Guinea Ecuatorial, postcolonialismo, globalización, migraciones, transnacionalismo.

Abstract: Historic structural conditions from colonialism, power political structures coming from franquismo, and current processes of capital globalization are factors explaining that Equatorial Guinea has become a postcolonial country expelling refugees and migrants to is former colonial metropole (Spain) since its independence in 1968. This migratory movement is an example in which we can observe how postcolonial structural conditions linking sending and receiving countries and social networks affect current refugees and migrants' dynamics as well as the development of postcolonial transnational relationships. Based on ethnographic research done with refugees and migrants from Equatorial Guinea settled in the Madrid metropolitan region, this article describes and analyzes how these factors affect their modes of incorporation and adaptation to this host metropolitan area while maintaining social and cultural relationships with their home societies.

Keywords: Equatorial Guinea, postcolonialism, globalization, migration, transnacionalism. 


\section{Introducción}

A comienzos de la pasada década, la periodista Begoña Aguirre (2001) publicaba en el periódico El País el artículo "Guineanos de cuarta generación" para destacar el aumento de inmigrantes procedentes de países de África occidental en la Comunidad de Madrid, especialmente de Senegal, Nigeria y Guinea Ecuatorial ${ }^{1}$. En este artículo, la periodista destaca que la diáspora ecuatoguineana constituida por una población heterogénea étnica y culturalmente -bubi, fang, ndowe, fernandinos, bisio o annoboneses- destacando de ella varios aspectos relevantes a considerar de las migraciones poscoloniales ${ }^{2}$. En primer lugar, que los ecuatoguineanos en Madrid, como en el resto de España, constituyen la diáspora con mayor trayectoria histórica debido a su pasado colonial y proceso de descolonización. En segundo lugar, sus distintos modos de incorporación (ver Portes y Bach 1985) y asentamiento en la región:

"Antes de 1968 (año de la independencia), muchos ecuatoguineanos vinieron a España a estudiar o como profesionales. Luego, en los setenta, con los regímenes de [Francisco] Macías y [Teodoro] Obiang, se produjo la gran salida, ya que hubo caos y represión", añade Bondjale. "Ahora sigue llegando gente, en general con visado de turista sin tener que recurrir al polizonaje ni a las pateras", matiza. Los ecuatoguineanos, como los latinoamericanos y los filipinos, pueden solicitar la nacionalidad española tras dos años de residencia.

Sin embargo, todavía hay un $20 \%$ de sin papeles. "Para nosotros ha sido más fácil integrarnos que para otros africanos”, explica

1 Desde la última década del siglo $X X$, un número cada vez mayor de migrantes procedentes de países de esta región se ha ido asentando no solo en la Comunidad de Madrid, sino en otras regiones españolas. Además de los ecuatoguineanos, con larga trayectoria migratoria en España, países como Senegal, Nigeria, Mali, Gambia o Ghana también se han convertido en países emisores de migrantes (ver INE 2016).

2 Como la mayor parte de los estados-nación poscoloniales africanos, Guinea Ecuatorial es un país con distintos grupos étnicos que, entre otros rasgos culturales, poseen sus propias lenguas. Mientras la mayor parte de su población pertenece a grupos fang (Sánchez Molina 2011), procedentes de la zona continental de Río Muni, la población bubi es mayoritaria en la isla de Bioko (Martín del Molino 1989; Fernández Moreno 2004) y los ndowé (Fons 2004) y bisio del litoral de la parte continental de Río Muni, también compuesto de varios grupos que fueron conocidos durante el periodo colonial como playeros (Combe, Bujeba, Benga o Bapuko), fernandinos (Aranzadi 2010), población criolla asentada fundamentalmente en Malabo y annobeses población de la isla de Annobón. 
Bondjale, "porque, al fin y al cabo, hablamos castellano y en los años de la colonia nos educaron diciéndonos que éramos españoles. Luego, al llegar, cuando empezaron a pedirnos la residencia supimos que era mentira" (Aguirre 2001).

$\mathrm{Y}$, en tercer lugar, que es la población inmigrante con mayor trayectoria organizativa en la Comunidad de Madrid, contando con el mayor número y diversidad de asociaciones con respecto a sus finalidades (culturales, asistenciales o políticas) y composición (estudiantes, refugiados o trabajadores), organizadas fundamentalmente por grupos de origen étnicos (ver también Blázquez Rodríguez, Mazarrasa Alvear y Otero García 2004; Vereda Muñoz 2003). Además de estos aspectos destacados por la periodista, hay que añadir que, frente a otros grupos migrantes africanos, se da ido dando un aumento significativo de mujeres migrantes y ciudadanas españolas con respecto a varones en la última década; como así se reflejan en los registros del INE (2016) sobre migración (más del 60 por ciento) y nacionalización (70 por ciento) en España (ver Figuras 1 y 2). Así y todo, estas cifras también indican, por otra parte, un descenso gradual de llegada de inmigrantes ecuatoguineanos desde 2010, para incrementarse levemente en 2014. El mayor número de inmigrantes registrados en el año 2014, por otra parte, corresponde a edades entre 20 y 34 años (39, 2 por ciento), destacando de un mayor número de personas en edad de trabajar (75, 82 por ciento) $)^{3}$.

Los niños en edades comprendidas entre 0 y 14 años suman un total de 264 personas, un 19,7 por ciento, y las personas mayores de 65 años, 58 personas, un total de 4,34 por ciento. En todas estas franjas de edad se registran más mujeres que hombres. 


\begin{tabular}{|l|c|c|c|}
\hline Ã̃ & TOTAL & MUJERES & HOMBRES \\
\hline 2004 & 6721 & 4366 & 2350 \\
\hline 2005 & 7616 & 5023 & 2591 \\
\hline 2006 & 7795 & 5112 & 2682 \\
\hline 2007 & 8663 & 5665 & 2997 \\
\hline 2008 & 7626 & 4776 & 2833 \\
\hline 2009 & 8459 & 5271 & 3167 \\
\hline 2010 & 8202 & 5232 & 2970 \\
\hline 2011 & 8504 & 5426 & 3078 \\
\hline 2012 & 8368 & 5348 & 3020 \\
\hline 2013 & 8449 & 5391 & 3058 \\
\hline
\end{tabular}

Figura 1: Población ecuatoguineana con permiso de residencia (2004-2013). Fuente: Instituto Nacional de Estadistica (INE, 2016)

\begin{tabular}{|c|c|c|c|}
\hline AÑO & TOTAL & MUJERES & HOMBRES \\
\hline 2005 & 455 & 319 & 136 \\
\hline 2007 & 354 & 256 & 97 \\
\hline 2008 & 369 & 249 & 120 \\
\hline 2009 & 289 & 199 & 89 \\
\hline 2010 & 442 & 303 & 139 \\
\hline 2011 & 384 & 253 & 131 \\
\hline 2012 & 344 & 247 & 97 \\
\hline 2013 & 712 & 504 & 207 \\
\hline 2014 & 339 & 249 & 89 \\
\hline
\end{tabular}

Figura 2: Concesión de nacionalidad española a población ecuatoguineana (2005-2014). Fuente: Instituto Nacional de Estadistica (INE, 2016) 
Guinea Ecuatorial ha sido desde su independencia de España (1968) hasta la actualidad un país eminentemente expulsor de refugiados (Ndongo 1977; Bolekia 2003) y de migrantes (Pereira Rodríguez 1994; Fons 2004) incluso en las últimas décadas de bonanza económica propiciada por las exportaciones de hidrocarburos (Aixalà 2013). Tanto la falta de reformas políticas democráticas desde su independencia, como de una justa redistribución de su riqueza explican, entre otros factores, la larga trayectoria, continuidad y aumento de su diáspora en la antigua metrópolis. Con todo, la falta de datos oficiales impide conocer la totalidad de población de origen ecuatoguineano en la Comunidad de Madrid o en el resto de España (Rodríguez García y San Román, 2007). Entre otras razones, porque además de estar constituida por exiliados, migrantes -con o sin documentos-, ciudadanos e hijos de progenitores españoles, no se dispone de censos oficiales de población ni en España ni en Guinea Ecuatorial desde su independencia ${ }^{4}$. Ante estas carencias, cifras oficiales ofrecidas por el Instituto Nacional de Estadística (INE 2016) pueden resultar orientativas a la hora de conocer, como mínimo, estadísticas referente a la población inmigrante regularizada y nacionalizada en la última década.

El caso del desplazamiento y asentamiento de la población de ecuatoguineana en la Comunidad de Madrid, en cualquiera de los casos, no hace más que incidir en la asociación que en los estudios migratorios se ha establecido entre condiciones estructurales de sociedades emisoras y receptoras (Kearny 1995; Grassmuck y Pessar 1991), dinámicas reticulares que favorecen su continuidad (Massey et al.1987) y transnacionalismo, propiciando vínculos socioculturales con las sociedades de origen (Basch, Glick Schiller y Szanton-Blanc 1994; Sánchez Molina 2005). De ahí que, junto a condiciones estructurales de exclusión y expulsión que se dan en Guinea Ecuatorial, los vínculos históricos y culturales con España debido al pasado colonial (Ndongo Bidyogo 1978; Bolekia Boleká 2003), el desarrollo de redes organizativas y de parentesco (Fons 2004) y el crecimiento económico en España hasta la crisis del 2008, sean también factores que expliquen la continuidad de las migraciones ecuatoguineanas a España y, particularmente, a la Comunidad de Madrid.

Mientras el Censo de Población 2015 de Guinea Ecuatorial de 2015 calcula una población de 1,222.442 habitantes, organizaciones multilaterales como Naciones Unidas, Banco Mundial o la Organización reducen estos cálculos. 
A pesar de su larga trayectoria histórica y relevancia sociocultural, sin embargo, las migraciones ecuatoguineanas han recibido poco interés en los estudios migratorios en España (Aixelà 2012a). Salvo descripciones generales en artículos y capítulos de libro a partir de la década de los noventa y de algunas monografías publicadas en la última década, pocos han sido los estudios que se han centrado en ella como fenómeno de especial interés social y cultural ${ }^{5}$. A partir de investigaciones etnográficas llevadas a cabo con población ecuatoguineana residente en la Comunidad de Madrid, con este artículo pretendemos contribuir a llenar este vacío enfocándonos en los distintos modos de incorporación de la población ecuatoguineana en la región, en sus procesos de adaptación y organización comunitaria ${ }^{6}$. Con esta finalidad, describimos y analizamos patrones migratorios dominantes para centrarnos en las distintas políticas que en España han ido aplicando como país receptor: como ciudadanos durante el último período de la colonia, estudiantes y apátridas/exiliados después de la descolonización o inmigrantes -con $\mathrm{y}$ sin documentos- en las últimas décadas.

\section{Estudiar y trabajar en la metrópolis}

La población ecuatoguineana comenzó a asentarse en España en el último periodo colonial, cuando el régimen franquista inicia el proceso de provincialización de los territorios del Golfo de Guinea forzado por las potencias internacionales surgidas tras la Segunda Guerra Mundial (Estados Unidos y la Unión Soviética), como consecuencia de la Guerra Fría y debido a las presiones que los estados poscoloniales afroasiáticos ejercen ante la Organización de las Naciones Unidas (ONU) para que se independicen las colonias europeas (ver Campos Serrano 2002). Tanto su provincialización en 1959, como posterior concesión de autonomía en 1963 resultó ser, sin embargo, un intento de integración nacional de las colonias fallido con el que el régimen franquista pretendía maquillar, siguiendo el modelo portugués, la persistencia de estructuras políticas y económicas coloniales.

5 Estos fueron publicados fundamentalmente a partir de la década de los noventa del siglo pasado (ver Sepa Bonaba 1990, 1993; Morales Lezcano 1993; Pereira Rodríguez 1994; Sipi 1995; Fons 2001), y de manera más sistemática en la última década (Fons 2004; Sipi 2005; Aixelà 2011; ver también Bardaji Ruiz 2006).

$6 \quad$ Parte del contenido de este artículo fue expuesto por los autores en la presentación "Diáspora ecuatoguineana y sistema de salud de la Comunidad de Madrid: procesos de incorporación y consideraciones socioculturales" en el Primer Seminario Internacional sobre Guinea Ecuatorial” en Madrid 2 de julio de 2014. 
Durante este periodo, la migración ecuatoguineana a España estuvo protagonizada fundamentalmente por estudiantes hijos de familias que durante el colonialismo disponía de los suficientes recursos para que estudiaran carreras universitarias o estudios superiores en la metrópolis, particularmente en Madrid y Barcelona, así como estudiantes que lograron obtener becas del estado español o de congregaciones religiosas establecidas en la colonia. Entre esta población, también llegaron jóvenes varones para hacer el servicio militar o ingresar en las academias militares (Pereira Rodríguez 1994). La llegada de estudiantes a la Comunidad de Madrid será, no obstante, una constante en los modos de incorporación de la población ecuatoguineana en España hasta la actualidad (Aixelà 2012b). De hecho, el número de visados de estudiante ha ido creciendo desde 2005, decreciendo levemente entre el año 2011 y 2013; dándose un mayor porcentaje de estudiantes varones con respecto a mujeres ${ }^{7}$. Con todo, hay que destacar que con respecto a otros grupos de inmigrantes africanos se da un mayor porcentaje de mujeres ecuatoguineanas con titulaciones superiores (Domingo y Brancós 2000).

También fueron pioneras de la migración ecuatoguineana a la región mujeres que vinieron a trabajar en el servicio doméstico de familias españolas que habían residido en la colonia (Pereira Rodríguez, 1994; Sipi, 2004). Así y todo, y como destaca Donato Ndongo-Bidyogo (1977), la migración ecuatoguineana a España durante el periodo colonial no fue numerosa. Al tiempo que este incipiente movimiento migratorio se iniciaba en distintas regiones de la metrópolis, líderes y opositores ecuatoguineanos que luchaban por la independencia, habían comenzado a exiliarse décadas antes en países del entorno como Nigeria, Camerún o Gabón.

\section{Ciudadanos, estudiantes y apátridas}

Después de la independencia, y una vez que el régimen de Francisco Macías Nguema se consolida en Guinea Ecuatorial, se inicia el primer

Como en otros paises africanos, después de la independencia fue significativo el desplazamiento de estudiantes para estudiar en el extranjero. En contextos de Guerra Fría, tanto el régimen de Macías como el de Obiang, enviaron ecuatoguineanos a estudiar a Cuba, la antigua Unión Soviética, China y Corea del Norte (Ndongo Biyogo, 1977; Aixalà, 2011). Durante la última década en España, el año 2014 fue el que registró el mayor número de ecuatoguineanos con visado de estudiante, 787, seguido del año 2010, con 778. En el año 2014, 416 visados de estudiantes fueron concedidos a varones, un 52,85 por ciento, y 371 a mujeres, un 47, 14 por ciento (INE 2016). 
exilio poscolonial como consecuencia de la férrea represión que Macías impone en el país tras el fallido golpe de estado de 1969 (ver Ndongo Bidyogo 1977; Muakuku 2000). Será España, junto a otros países del entorno, particularmente Gabón, Camerún y Nigeria, los principales lugares de destino del primer exilio poscolonial ecuatoguineano (Bolekia 2003). Macías deja repentinamente sin nacionalidad a los estudiantes ecuatoguineanos que se encontraban en España. El régimen franquista, que no se había adherido a las convenciones internacionales que sobre derecho de asilo se habían establecido después de la Segunda Guerra Mundial, no los reconoce como refugiados ${ }^{8}$. Hasta tal punto que, en la primera mitad de la década de los setenta, la mayoría de los estudiantes ecuatoguineanos se encontraron como apátridas en España, privados de nacionalidad y de cualquier tipo de permiso que les permitiera residir y trabajar en el país. Con poca repercusión en los medios de comunicación controlados por el régimen, esta inusitada situación a la que tienen que enfrentarse los refugiados ecuatoguineanos, no encontraría eco en la opinión pública española hasta varios años más tarde, una vez que se inicia en España la transición a la democracia 9 .

La mayoría de los aproximadamente 6.000 guineanos ecuatoriales que viven en España se encuentran en serias dificultades derivadas de su situación como indocumentados o apátridas que sufren desde que un decreto del presidente guineano, Macías Nguema, les privó de su nacionalidad o les vetó el derecho a conseguir pasaporte de su embajada en Madrid (...) El principal núcleo se encuentra en Barcelona y el resto se halla esparcido entre Madrid y otras ciudades de la Península. La tercera parte de la cifra total está compuesta por mujeres y hay un número creciente de niños, aunque la mayoría de los ecuatoguineanos nació cuando su país de origen pertenecía a España como provincia de ultramar. Los

$8 \quad$ Hasta la Ley de Asilo de 1984, España no se adhiere a las convenciones internaciones que regulan el derecho de asilo después de la Segunda Guerra Mundial y que se adecúa a las normativas de la Unión Europea en 1994 y 2009. En ésta última, Ley 12/2009 (pg. 2) se especifica que el ordenamiento jurídico español se acoge a la Primera Fase del Sistema Europeo Común de Asilo, tal y como destaca en el Programa de La Haya de 2004, partiendo de los derechos establecidos sobre el estatuto y protección jurídica internacional de los refugiados por la Convención de Ginebra (1951) y el Protocolo de Nueva York (1967).

9 Con artículos como el de A. Méndez (1976) titulado "Sigue la tragedia de 8.000 guineanos", Rafael Fraguas (1978) "Seis mil guineanos viven marginados en España como indocumentados o apátridas" o fosé Guerrero Martín (1978) "Seis mil ecuatoguineanos viven como apátridas en España”. 
problemas más importantes por los que atraviesan se sitúan en la esfera laboral, dadas las enormes dificultades con las que tropiezan a la hora de encontrar trabajo, pese a que muchos de ellos poseen cualificación laboral... (Fraguas 1978).

La falta de información sobre la dictadura de Macías en Guinea Ecuatorial y la indefensión en la que se encontró su diáspora en España durante el último periodo franquista se debió a la prohibición explícita del franquismo sobre cualquier acontecimiento relacionado con la antigua colonia, que fue catalogada como "materia reservada". En esas fechas se publica en España el libro de Donato Ndongo Bidyogo (1977) Historia y tragedia de Guinea Ecuatorial, en el que el escritor exiliado ecuatoguineano denuncia la dramática y absoluta indefensión a la que tienen que enfrentarse en España. Todos aquellos que se quedaron sin autorización para residir en territorio español, tuvieron entonces que vivir y trabajar como indocumentados y depender de la ayuda que parientes, amigos, compatriotas $\mathrm{u}$ organizaciones podían ofrecerles. Como reacción, grupos de ecuatoguineanos comenzaron a organizarse en Barcelona y Madrid (Muakuku 2000) y a establecer las primeras asociaciones en España ${ }^{10}$.

Según una encuesta llevada a cabo por ASODEGUE en 1978 entre 1.300 ecuatoguineanos residentes en España se destaca que la mayor parte se había desplazado por motivos de estudios o políticos. Y que tan solo un 10 por ciento lo había hecho por motivos laborales. Para entonces se estimaba que la población ecuatoguineana en España rondaba entre 15.000 y 20.000 personas, concentrándose principalmente en Madrid, Barcelona y Valencia - seguidas por Bilbao, Las Palmas de Gran Canaria, Valencia, Sevilla y Zaragoza. Según esta misma encuesta, de todos ellos, solo una tercera parte (unos 5.000 ecuatoguineanos) pudo mantener su nacionalidad española tras la independencia, quedando el resto como apátridas o indocumentados. De esta población, se estimaba que unas 3.000 personas residían en la región metropolitana de Madrid, concentrándose en los barrios de Aluche y Batán de la capital y en la región sur de la Comunidad de Madrid, principalmente en Móstoles (ver Colectivo IOE 1987).

10 Entre ellas, la asociación ndowé Maleva (1977) o la Asociación Cultural Bubi (1979). 


\section{Segundo régimen nguemista y desplazamientos}

Con el derrocamiento de Francisco Macías Nguema encabezado por su sobrino Tedoro Obiang Nguema en 1979 -jefe de las fuerzas armadas formado en la Academia Militar de Zaragoza durante el franquismo-, se inicia nuevamente un segundo periodo fallido para la democracia en Guinea Ecuatorial y, por lo tanto, para el regreso de su diáspora en España ${ }^{11}$. Tras el golpe de estado, Teodoro Obiang parecía dispuesto a sacar al país del aislamiento político y del empobrecimiento económico al que lo había sumido el anterior régimen. Al tiempo que permite a Naciones Unidas iniciar programas de desarrollo en el país, firmaba el Acuerdo de Amistad y Cooperación con España en 1980 (Wood 2004) y la Universidad de Educación a Distancia (UNED) se hace cargo un año más tarde de la educación universitaria estableciendo centros en Malabo y Bata.

Lejos de iniciar las reformas políticas que permitieran el establecimiento de instituciones democráticas en el país centroafricano, Teodoro Obiang consolida un régimen totalitario, denominado por Muakuku (2000) "segundo régimen nguemista", impulsando a su diáspora en España a organizarse políticamente contra su dictadura. Entre los días 1 y 3 de abril de 1983 se lleva a cabo una convención de representantes de distintas asociaciones y organizaciones ecuatoguineanas en Zaragoza, en la que se crea la Junta Coordinadora de las Fuerzas de Oposición de Guinea Ecuatorial (JCFOGUE) ${ }^{12}$. El 25 de febrero de 1983 se funda en Madrid el Partido del Progreso de Guinea Ecuatorial que lidera Severo Moto. Y dos años más tarde, la Asociación para el Progreso de Guinea Ecuatorial (APGE) (ver Muakuku 2000).

Con el nuevo régimen de Obiang y la pobreza en la que se encuentra sumido el país tras el anterior régimen continúan los desplazamientos de ecuatoguineanos a países del entorno, como Camerún y Gabón, y a España propiciados fundamentalmente por redes de parentesco. En estos casos, el patrón migratorio dominante parte de la ayuda familiar que ciudadanos y residentes en España ofrecen a sus parien-

11 Teodoro Obiang encabeza un golpe de estado derrocando a Macías el 3 de agosto de 1979, abriendo el pais a la ayuda internacional (Muakuku 2000: 73).

12 Surgen entonces seis formaciones politicas: A.N.R.D., FRELIGE, Grupo para la Reforma Politica, MOLIFUGE, Partido del Progreso, Unión Bubi. Sin embargo, según distintos autores (Linniger-Goumaz 1994; Nsé Angüé 2011), las ambiciones personalistas de sus lideres hicieron fracasar estos proyectos. 
tes más cercanos (madres, padres o hermanos) que viajan al país con visado de turista. Puesto que estas estancias suelen extenderse más allá de los tres meses expedidos en sus visados, los recién llegados terminan residiendo en España sin autorización. En el caso de la Comunidad de Madrid, Teresa Pereira Rodríguez (1994) destaca que los ecuatoguineanos, que durante la década de los ochenta siguen sin ser reconocidos por los gobiernos españoles como refugiados políticos, dependían de la ayuda de familiares, amigos o de organizaciones no gubernamentales. En las entrevistas realizadas por la autora, los ecuatoguineanos declaraban la búsqueda de trabajo, la ampliación de estudios, la reagrupación familiar o la salud como motivos principales para su desplazamiento. A pesar de su capital humano y cultural, la autora destaca que los ecuatoguineanos encontraban trabajos para los que se requerían poca (ver también Rodríguez García y San Román, 2006).

La presencia de redes sociales, tanto de parentesco como comunitarias, que facilitan la llegada e incorporación al país de los ecuatoguineanos es uno de los motivos que más se esgrimen en las narrativas de nuestros informantes a la hora de destacar los motivos que les empujaron a emigrar a España. Estas redes sociales, como se ha señalado anteriormente, resultan de gran importancia para entender los actuales desplazamientos de población; redes que, debido a las dinámicas de los actuales movimientos de población y a los medios de comunicación intensifican los vínculos de los actuales inmigrantes con sus sociedades de origen, y viceversa (Sánchez Molina 2005). Éstas pueden constituirse a partir de relaciones de intercambios de reciprocidad que pueden llegar a adoptar un amplio abanico de relaciones y dinámicas en cuanto a sus formas y funciones (Fons 2004).

La falta de libertad y oportunidades laborales en Guinea Ecuatorial, la ampliación de formación profesional y académica, así como la reunificación familiar, son entre otros, factores que afectan la continuidad de los desplazamientos ecuatoguineanos a España (Morales Lezcano 1993). Entre estos nuevos migrantes, continúan llegando jóvenes ayudados por familiares para continuar con estudios superiores o universitarios. La falta de ayuda institucional, sin embargo, hace que la mayoría de ellos tengan que terminar compaginando estudios y trabajos. El mercado laboral al que han podido acceder desde entonces, con respecto a la anterior generación, es en el sector de servicios: los varones como repartidores, camareros, conductores, carpinteros o electricistas, y las mujeres en el mercado laboral reproductivo, trabajando en el servicio doméstico (Puerta 1987). Los hombres y las pocas mu- 
jeres que llegaron entre los años sesenta y ochenta con becas de estudio o con financiación de sus familias, una vez que finalizaron sus estudios y pudieron regularizar su situación, gran parte de ellos accediendo a la ciudadanía española, e incorporarse a un mercado laboral profesional para trabajar como médicos, profesores, enfermeros/as o abogados.

Como destaca el Colectivo IOE (1987), la legislación española, basada fundamentalmente en criterios funcionalistas, ha sido generalmente restrictiva para los inmigrantes, particularmente cuando estos después de haber trabajado regularmente y cotizado en la Seguridad Social quedan en el paro, ya que, una vez que quedan desempleados pierden inmediatamente sus permisos de residencia. Ante esta situación de desprotección laboral, grupos de ecuatoguineanos en la región metropolitana intentan responder fundando en Móstoles en 1992, la Asociación de los Emigrantes y Trabajadores Ecuatoguineanos en España. ${ }^{13}$ A este respecto, hay que destacar que los partidos de la oposición en el exilio también constituyen, por otra parte, redes de apoyo, aunque manteniendo, por otra parte, otros tipos de relaciones particulares de rivalidad y desconfianza (Galiano Sierra 2011).

\section{Democracia fallida, petróleo y exclusión social en Guinea Ecuatorial}

La década de los noventa estuvo marcada por las leves reformas políticas que el régimen de Obiang realizó en 1991 obligado por la presión internacional. Entre éstas, el régimen se reconoce partidos políticos y permite la celebración de elecciones (Campos Serrano 2002). A finales de los noventa, por otra parte, la economía ecuatoguineana experimenta un crecimiento sin precedentes debido a la extracción de petróleo. ${ }^{14}$ Guinea Ecuatorial pasa entonces de ser un país prácticamente dependiente de la ayuda internacional (Abaga 1997), a uno de los países con mayor exportación de petróleo del continente africano (Apple 2012a). Hasta tal punto que, en solo una década, sus índices del Producto Interior Bruto (PIB) se situaron por delante de países que

13 En 1995, se fundó la Asociación de Refugiados Ecuatoguineanos en España (A.R.E.G.E.) y la Asociación de Solidaridad Democrática con Guinea Ecuatorial (ASODEGUE). En 1992, se funda en Cataluña la Asociación de Mujeres E'Waiso Ipola (ver Sipi 1997).

14 Detrás de Ángola y Nigeria, Guinea Ecuatorial se convirtió en el mayor exportador de petróleo del continente africano, llegando a representar alrededor del 80 por ciento del Producto Interior Bruto de la economía del país (ver Campos Serrano 2011). 


\section{integran la Unión Europea ${ }^{15}$.}

Así y todo, los leves cambios políticos introducidos por el régimen y su acelerado crecimiento económico no contribuyeron ni a la democratización del país, ni a mejorar el bienestar social de la mayor parte de su población que, por el contrario, continúa viviendo con índices muy bajos de pobreza. Si bien la riqueza generada por el petróleo resulta visible en las grandes infraestructuras construidas en el país en los últimos años (carreteras y obras relacionadas con las explotaciones petrolíferas), ésta ha ido concentrándose en sus élites gobernantes ${ }^{16}$. Y en los sucesivos informes internacionales se ha ido reiterando que solo una mínima parte de estos ingresos han sido destinados a programas de desarrollo que mejoren las condiciones de vida, salud, educación o trabajo de la mayor parte de su población (Lawal 2007; Holmes y Villar 2008; Gallón 2001). La economía del petróleo, por el contrario, ha contribuido al mantenimiento de las viejas estructuras autárquicas nguemistas que se han visto reforzadas por las compañías extranjeras que se han ido estableciendo en el país (Esteban 2009; McSherry 2006; Appel 2012a).

Además de altos índices de pobreza entre la mayor parte de la población, la falta de democracia y la violación de derechos humanos son aspectos que continúan destacándose en los informes internacionales; reiterándose hechos relacionados con el fraude electoral, la falta de libertad de circulación, represión y tortura (UNHCR 2001; Vine 2009; Amnistía Internacional 2009). Éstas y otras prácticas han impedido, como destaca Nsé Angüe (2011), el desarrollo de una sociedad civil que posi-

15 De los 130 millones de dólares del PIB que se registraba a comienzos de la década de 1990, según datos del Fondo Monetario Internacional, en el año 2004 registraba 2.368 millones de dólares. En 2006, el 94 por ciento de su PIB procedía del petróleo. En el año 2008, la industria representaba el 99.3 por ciento de las exportaciones del país y el 98 por ciento de los ingresos del gobierno (Apple 2012a).

16 Hannah Appel (2012b) analiza como "violencia infraestructural" las nuevas construcciones públicas que se han ido erigiendo en el país, asi como los recintos residenciales y comerciales amurallados donde residen y trabajan los migrantes estadounidenses contratados por las compañias de petróleo. Según la antropóloga, "unn nuevo apartheid generado por la industrial global del petróleo" y que contrasta con la vida cotidiana de la mayor parte de la población ecuatoguineana que vive con electricidad esporádica, enfermedades endémicas como fiebres tifoideas y malaria y sin agua potable en sus casas. Según Appel (2012b: 441-42), "tanto el modelo de ciudad-compañia (company town model) como la privatización del espacio urbano produce generalmente formas familiares de violencia" que incluye altos niveles de control de trabajadores, la supresión de la organización laboral y deliberadas reglamentaciones residenciales que refuerzan las jerarquías raciales; segregación espacial que la autora denomina "capitalismo zonal". 
bilite la participación democrática y la defensa de los derechos civiles en Guinea Ecuatorial.

Con respecto al ámbito laboral, tampoco se dan mecanismos de participación en el mercado de trabajo asalariado entre trabajadores y empleadores y las normativas al respecto apenas son tenidas en cuenta; éste se caracteriza sobre todo por su politización y el clientelismo ${ }^{17}$. De tal manera que, puesto que las principales empresas en el país están controladas por la élite gobernante, las posibilidades de encontrar o mantener un empleo dependen, en gran medida, de las adhesiones de los trabajadores al partido gobernante (Galiano Sierra 2011; Campos Serrano y Micó Abogo 2009).

No es de extrañar, por lo tanto, que, a pesar del crecimiento económico, el desplazamiento de ecuatoguineanos a España creciera gradualmente en pleno auge de la industria petrolífera ${ }^{18}$ Así y todo, también hay que destacar que con la expansión de la industria del petróleo Guinea Ecuatorial se convirtió en uno de los países denominados del "sur global" receptor de migrantes internacionales y del retorno de migrantes ecuatoguineanos en el extranjero, particularmente de España, particularmente como consecuencia de la crisis económica (Aixalá 2012a).

\section{Continuidad de la diáspora ecuatoguineana en la Comu- nidad de Madrid}

Si las condiciones estructurales de exclusión y expulsión en el país de origen, los vínculos histórico-culturales y la presencia de familias y organizaciones explican la elección de la Comunidad de Madrid como

17 El mercado laboral en Guinea Ecuatorial lo constituye fundamentalmente un sector formal que se concentran en la administración del estado, $y$ en sectores de servicios y construcción en empresas privadas. El sector informal, no asalariado, se da en el trabajo agrícola y en el pequeño comercio (Campos Serrano y Micó Abogo 2009). Solo en el sector petrolero se formalizan contratos, aunque esta industria se basa en un sistema de subcontratación, por lo que el contrato laboral es entre los trabajadores y la agencia intermediaria de contratación controlada por el aparato del Estado (Galiano Sierra 2011). Estos suelen ser temporales, de baja cualificación y sin garantías de seguridad (Appel 1012a).

18 Según el Instituto Nacional de Estadística (INE 2016), el número de inmigrantes ecuatoguineanos en España en el año 2000 sumaba un total de 10.841 personas incrementándose en un 74,6 por ciento hasta alcanzar un total de 18.928 personas en el 2005, y un 21,05 por ciento hasta el 2009. De tal manera que, según estas cifras oficiales, habia en España residiendo al final de la primera década 22.914 ecuatoguineanos. 
uno de los principales destinos de la población ecuatoguineana, a éstas habría también que incluir el desarrollo económico de la región, sobre todo, desde mediados de los noventa. Mientras el municipio de Móstoles continúa siendo uno de los principales lugares de asentamiento de la diáspora ecuatoguineana, otros municipios de la región sur, como Fuenlabrada y Alcorcón, y del noreste, como Alcalá de Henares, se han convertido también en lugares de destino en las últimas décadas ${ }^{19}$. De hecho, según los demógrafos Domingo, López Falcón y del Rey (2010: 12), hacia finales de la década anterior casi la mitad de los ecuatoguineanos inmigrantes en España residían en la Comunidad de Madrid. ${ }^{20}$

A finales de los noventa, en la Comunidad de Madrid se dio un crecimiento económico significativo debido al desarrollo que experimentan sectores relacionados con servicios, transporte, construcción o telecomunicaciones. Hasta tal punto que, a comienzos de la primera década del presenta siglo, la Comunidad de Madrid se situó como una de las regiones de la Unión Europea con mayor índice de crecimiento económico, creación de empleo y de mayor recepción de inmigrantes extracomunitarios (García Ballestero y Sanz Berzal 2004). La necesidad de mano de obra que demandaba hasta recientemente tanto la economía formal como informal en la región hace que hasta hace muy pocos años se fuera intensificando la llegada y el asentamiento de población inmigrante, fundamentalmente procedente de países latinoamericana y africanos.

Hasta la crisis financiera de 2008, los ecuatoguineanos que se asentaban en la Comunidad de Madrid solían encontrar trabajo fundamentalmente en los sectores relacionados con los servicios, en el caso de los hombres y las mujeres, y en la construcción en el caso de los hombres. Un mercado laboral que, como en el caso de otros grupos de migrantes, se caracterizó por su segmentación étnica y por género (Martínez Veiga 2004). De tal manera que las mujeres encontraban trabajo fundamentalmente en el mercado laboral reproductivo (servicio doméstico y el cui-

19 Según cifras de la Encuesta de Población Activa de 2012, en la región sur de la Comunidad de Madrid se habian registrado 3.843 ecuatoguineanos, en Madrid, 1.320, en el nordeste, 1183, en el sureste 156, en la Sierra Noroeste 32, y Sierra Norte 17; siendo Fuenlabrada (1025), Móstoles (955), Alcalá de Henares (590), Torrejón de Ardoz (547), Leganés (460), Parla (409), Getafe (264).

20 Citando fuentes provisionales del INE sobre inmigrantes de paises africanos en España, la Comunidad de Madrid registraba 6.614 inmigrantes ecuatoguineanos de un total de 14.497 en todo el territorio español, seguida dela Comunidad Valenciana con 2.164, Cataluña con 1.678, Aragón con 736, País Vasco 760 y Canarias 521 (ver Domingo, López Falcón y del Rey 2010: 13) 
dado de niños y mayores) y los varones en los trabajos peor remunerados en el sector de servicios y construcción (ver también Ballestero y Sanz Berzal 2004).

En cuanto al mercado laboral segmentado por género hay que destacar que el aumento de la demanda en trabajos relacionados con servicio doméstico y el cuidado ha influido también en la llegada de un mayor número de mujeres ecuatoguineanas en lo que va de siglo. Según nuestras informantes, suele resultar relativamente más fácil encontrar trabajo en el servicio doméstico incluso sin contrato. Como en el caso de gran parte de ellas, y como destacaba Sipi Mayo (2004: 65), el 65 por ciento de las mujeres ecuatoguineanas en España trabaja en el servicio doméstico - ya sea como internas en hogares españoles, en empresas que ofrecen servicios de asistencia o trabajando por horas en domicilios particulares. Y con frecuencia estos trabajos lo realizan sin un contrato laboral.

Con todo, el mercado laboral al que ha tenido acceso la población ecuatoguineana está condicionado por el periodo en que se produjo la llegada. Como se ha destacado previamente, los hombres y las pocas mujeres con estudios universitarios o profesionales que llegaron antes de la década de los noventa accedieron a puestos profesionales dentro y fuera de las administraciones públicas como ciudadanos españoles. Sin embargo, los que se han ido incorporando posteriormente han accedido a trabajos poco demandados por los españoles (almacenes de grandes superficies, de empresas de transporte, cocinas de restaurantes pertenecientes a cadenas o cadenas de montaje).

\section{"Viajes de ida y vuelta" en tiempos de crisis}

...los guineanos no vienen en patera, vienen en barco o en avión. Éramos colonia española, viajábamos con pasaporte español, y ahora venimos con visado de turista (Informante, Galiano Sierra 2011).

Aunque si bien la política migratoria beneficia, en alguna medida, a los ecuatoguineanos con respecto a otros grupos migratorios extracomunitarios, para conseguir la nacionalidad, ésta no deja de imponerles los mismos obstáculos a la hora de migrar y asentarse. Una vez que los ecuatoguineanos consiguen el permiso de residencia, la legislación española les otorga el derecho de acceder a la ciudadanía después de dos años de residencia. Una reducción temporal que también se aplica a inmigrantes latinoamericanos, Andorra y Filipinas, mientras que al 
resto de inmigrantes que no proceden de la Unión Europea les exige diez años de residencia. No en vano, y como se ha destacado previamente, la concesión de la nacionalidad española a ecuatoguineanos ha ido creciendo en la última década.

Desde 2009 el empleo se hizo más precario, aumentó el empleo en el sector informal y el desempleo, el servicio doméstico, el autoempleo como mecánicos, modistas e incluso la prostitución en el caso de las mujeres. La recesión económica que se intensifica a finales de la última década ha originado mayores dificultades para encontrar trabajo, afectando particularmente a las poblaciones migrantes. Los altos índices de desempleo, los recortes sociales y las reformas laborales llevadas a cabo por los distintos gobiernos como consecuencia de esta crisis ha dejado, en cualquiera de los casos, en situación de mucha mayor vulnerabilidad a los inmigrantes ecuatoguineanos. Para ellos, como para el resto de los inmigrantes extracomunitarios, quedarse en paro tiene, como se ha destacado anteriormente, mayores consecuencias que para los ciudadanos; ya que las restricciones de la legislación española hacen que se queden inmediatamente sin permiso de residencia. De ahí que, como entre otros grupos de migrantes, muchos ecuatoguineanos se hayan visto obligados a regresar a Guinea Ecuatorial, como observamos entre nuestros informantes y se registran en estadísticas oficiales en España. Como destacan Campos Serrano y Micó Abogo (2009), por otra parte, el crecimiento de la explotación petrolífera ha generado un importante movimiento de población, tanto dentro de Guinea Ecuatorial, particularmente del campo a las ciudades, de migrantes ecuatoguineanos retornados y de otros países africanos transformando en la estructura de su mercado laboral.

Ante la situación de crisis económica y de desempleo, por otra parte, muchos de nuestros informantes han tenido que recurrir a la ayuda que tanto las redes de parentesco y organizaciones comunitarias le han podido ofrecer llenando el vacío que, en la provisión de ayuda social a los migrantes, dejó de ofrecer las administraciones públicas de la Comunidad de Madrid (Galiano Sierra 2011). Sobre todo, en el caso de los migrantes ecuatoguineanos que se han visto obligados a residir y trabajar sin permiso. Junto a esta exclusión política, hay que señalar otras, como destaca Aixalà (2012b; 2013), de carácter racista y xenófobo a las que la tienen que enfrentarse cotidianamente. Además de las redes basadas en el parentesco, las organizaciones comunitarias (asociaciones) también han actuado como redes de apoyo para el asentamiento, la búsqueda de vivienda, empadronamiento, formación y búsqueda de 
trabajo; al tiempo que fomentan la continuidad de vínculos identitarios con sus sociedades de origen a través del folklore, el aprendizaje del idioma o la celebración de fiestas patronales propias de Guinea Ecuatorial.

\section{Conclusiones}

Si condiciones de carácter histórico-estructural vinculadas con el colonialismo, los procesos de descolonización y las actuales dinámicas globales del capitalismo explican los actuales desplazamientos de las poblaciones africanas a los países de la Unión Europa (Nartínez Veiga 2011), las políticas migratorias de exclusión han ido incidiendo en sus modos de incorporación y adaptación con significativas consecuencias socio-culturales de carácter transnacional.

Desde los prolegómenos de los procesos de independencia, las ex colonias africanas se convirtieron en expulsoras de refugiados y migrantes que se han ido asentando en las antiguas metrópolis europeas con expectativas de retorno; esperando que las condiciones de los países de origen posibilitaran su regreso y reasentamiento definitivo. La falta de expectativas para ese retorno ha hecho que, en el caso de las migraciones ecuatoguineanas a España no solo se hayan mantenido cincuenta años más tarde de su independencia, sino aumentando y diversificando desde entonces. Y a pesar de sus vinculaciones históricas, culturales y sociales con España, las políticas migratorias, por otra parte, no han hecho más que imponer obstáculos infranqueables que han impedido a muchos ecuatoguineanos migrar, residir y trabajar de manera regular; viéndose obligados, en consecuencia, a incorporarse y asentarse clandestinamente para trabajar en un mercado laboral informal segmentado, poco remunerado y más allá de su capital humano y cultural.

\section{Bibliografía}

Abaga, Fernando (1997) La Ayuda Externa en el Desarrollo de Guinea Ecuatorial. Madrid: Los Libros de la Catarata.

Aguirre, Begoña (2001) “Guineanos de cuarta generación.” Publicado en el periódico El País el jueves 23 de agosto de 2001.

Aixelà, Yolanda (2013) "Of Colonists, Migrants and National Identity. The Historic Difficulties of the Socio-Political Construction of Equatorial Guinea." Nordic Journal of African Studies, 22(1-2): 49-71.

Aixelà, Yolanda (2012a) "Entre las dictaduras y el petróleo: las migraciones transnacionales de Guinea Ecuatorial.” Revista andaluza de antropología, 3: 80-93.

Aixelà, Yolanda (2012b) "Estudiantes transnacionales de Guinea 
Ecuatorial desde una perspectiva postcolonial.” Realis, 2(2): 117-130.

Aixelà, Yolanda (2011) Guinea Ecuatorial: Ciudadanías y migraciones transnacionales en un contexto dictatorial africano. Vic: Ceiba Edicions.

Amnistía Internacional (2009) "Informe 2009 Amnistía Internacional. El estado de los derechos humanos en el mundo: Guinea Ecuatorial." http:// report2009.amnesty.org/es/regions/africa/equatorial-guinea (acceso $21 \mathrm{de} \mathrm{ju-}$ nio de 2014).

Appel, Hannah (2012a) "Offshore work: Oil, modularity, and the how of capitalism in Equatorial Guinea.” American Ethnologist, 39(4): 692-709.

Appel, Hannah (2012b) "Walls and white elephants: Oil extraction, responsibility, and infrastructural violence in Equatorial Guinea." Ethnography, 13(4): 439-465.

Aranzadi, Isabella de (2010) “A Drum's Trans-Atlantic Journey from Africa to the Americas and Back after the end of Slavery: Annobonese and Fernandino musical cultures." African Sociological Review/Revue Africaine de Sociologie, 14(1): 20-47.

Bardají Ruiz, Federico (2006) Literatura sobre inmigrantes en España. Madrid: Ministerio de Trabajo y Asuntos Sociales.

Basch, Linda, Nina Glick Schiller, and Cristina Szanton-Blanc (1994) Nations Unbound: Transnationalized Projects and the Deterritorialized Nation-State. New York: Gordon and Breach

Blázquez-Rodríguez, María Isabel, Laura Otero y Lucía Mazarrasa (2004) "Aproximación a las asociaciones africanas como agentes de salud en sus comunidades.” Revista Ofrim, 11:71-90.

Bolekia Boleká, Justo (2003) Aproximación a la historia de Guinea Ecuatorial. Salamanca: Amarú Ediciones.

Campos Serrano, Alicia (2011) Petróleo y Estado postcolonial: transformaciones de la economía política en Guinea Ecuatorial. Serie Avances de Investigación, $\mathrm{n}^{\circ}$ 54. Madrid: Fundación Carolina.

Campos Serrano, Alicia (2002) De colonia a Estado: Guinea Ecuatorial, 1955-1968. Madrid: Centro de Estudios Políticos y Constitucionales.

Campos Serrano, Alicia y Plácido Micó Abogo (2009) Trabajo y libertades sindicales en Guinea Ecuatorial. Madrid: Fundación Paz y Solidadridad "Serafín Aliaga"-CCOO y Confederación Internacional de Organizaciones Sindicales Libres (CIOSL)

Colectivo IOE (1987) Los inmigrantes en España. Documentación Social, 66. Madrid: Cáritas española.

Domingo, Andreu, Diana López Falcón y Alberto del Rey (2010) Current Status and Trends of African Migration to Spain. Papers de Demografia. Barcelona: Centre d'Estudis Demogràfics.

Domingo, Andreu e Inés Brancó (2000) “Población femenina de nacio- 
nalidad extranjera en la provincia de Barcelona, 1996.” Papers 60: 305-326.

Esteban, Mario (2009) "The Chinese Amigo: Implications for the Development of Equatorial Guinea.” The China Quarterly, 199: 667-685.

Fernández Moreno, Nuria (2004) "Jefaturas, reinado y poder colonial: evolución de la estructura política de los Bubis en la isla de Bioko". En Aurora Marquina (Comp.), El ayer y hoy: lecturas de antropología política Madrid: Cuadernos de la UNED, Vol. I, pp.181-214.

Fons, Virginia (2004) Entre dos aguas. Etnomedicina, procreación y salud entre los ndowé de Guinea Ecuatorial. Barcelona: Ceiba Ediciones.

Fons, Virginia (2001) "Historia de un Viaje sin retorno. Proceso migratorio de la población de Guinea Ecuatorial a España.” En Luis Ondo Ayang, Marcelino Bondjale Oko, Humberto Riochí Bobuiche y Francisco Zamora Loboch (ed.) Misceláneas Euro-Africanas ofrecidas al profesor Max LinigerGoumaz. Madrid: Editorial Claves para el Futuro, pp. 297-306.

Fraguas, Rafael (1978) "Seis mil guineanos viven marginados en España. Como indocumentados o apátridas”. En El País, sábado 29 de julio.

Galiano Sierra, Enrique (2011) "Migrantes, salud e instituciones sanitarias: aproximaciones etnográficas sobre la atención sanitaria a inmigrantes ecuatoguineanos en la Comunidad de Madrid." Trabajo Doctoral (DEA). UNED (sin publicar)

Gallón, Gustavo (2001) Report on the human rights situation in the Republic of Equatorial Guinea. Commission of Human Rights. United Nations.

García Ballestero, Aurora y Bernardino Sanz Berzal (2004) Inmigración y sistema productivo en la Comunidad de Madrid. Madrid: Consejería de Economía e Innovación Tecnológica.

Grasmuck, Sherry y Patricia R. Pessar, Patricia R. (1991) Between Two Islands. Dominican International Migration. Berkeley: University of California Press.

Guerrero Martín, José (1978) "Seis mil ecuatoguineanos viven como apátridas en España”. En La Vanguardia, martes, 28 de agosto.

Holmes, Rebeca y Eliana Villar (2008) La protección social y los niños en el África Occidental y Central. Estudio de caso: Guinea Ecuatorial. Malabo: UNICEF Guinea Ecuatorial.

INE, Instituto Nacional de Estadística (2016) "Flujo de inmigración procedente del extranjero por año, sexo, grupo de edad y país de nacimiento."

http://www.ine.es/jaxi/Datos.htm?path=/t20/p277/prov/e01/ $10 / \&$ file $=01004$. px $\&$ type $=$ pcaxis (último acceso $12 \mathrm{de}$ abril de 2018)

Kearny, Michael (1995) "The local and the Global: The Anthropology of Globalization and Transnationalism" Annual Review of Anthropology 24: 247-265.

Lawal, B. O. (2007) “A Comparative Analysis of Secondary Education 
in Four Central African Countries (Burundi, Rwanda, Chad and Equatorial Guinea).” The Social Sciences, 2 (2): 181-191.

Ley 12/2009 Reguladora del derecho de asilo y de la protección subsidiaria. Madrid: BOE, núm. 263 de 31 de octubre.

Linniger-Goumaz, Max (1994) África y las democracias desencadenadas. El caso de Guinea Ecuatorial. Madrid: Editorial Claves para el Futuro.

Massey, Douglas; Alarcón, Rafael; Durand, Jorge; González, Humberto (1987) Return to Aztlan. The Social Process of International Migration from Western Mexico. Berkeley: University of California Press.

Martin del Molino, Amador (1989) Los Bubis. Ritos y creencias. Malabo: Centro Cultural Hispano-Guineano.

Martínez Veiga, Ubaldo (2011) Inmigrantes africanos, racismo, desempleo y pobreza. Barcelona: Icaria.

Martínez Veiga, Ubaldo (2004) Trabajadores invisibles. Precariedad, rotación y pobreza de la inmigración en España. Madrid: Catarata.

Méndez, A. (1976) "Sigue la tragedia de 8.000 guineanos”. En Blanco y Negro el 7 de julio.

McSherry, Brendan (2006) "The political economy of oil in Equatorial Guinea.” African Studies Quarterly, 8 (3): 23-45.

Morales Lezcano, Víctor (1993) Inmigración africana en Madrid: Marroquíes y guineanos (1975-1990). Madrid: UNED.

Muakuku Rondo Ibango, Fernando (2000) Guinea Ecuatorial. De la esclavitud colonial a la dictadura nguemista. Barcelona: Ediciones Carena.

Ndongo-Bidyogo, Donato (1985) "España y Guinea (1958-1968)." Suplemento Historia 16, pp. 107-128.

Ndongo Bidyogo, Donato (1977) Historia y tragedia de Guinea Ecuatorial. Madrid: Editorial Cambio 16.

Nsé Angüe, Amancio-Gabriel (2001) La democracia en Guinea Ecuatorial. Dificultades de un proceso. Madrid: UNED.

Pereira Rodríguez, Teresa (1994) "Inmigrantes de Guinea Ecuatorial en Madrid, a través de fuentes orales.” En Morales Lezcano, V. (ed; coord.) II Jornadas sobre fuentes orales y gráficas para el estudio de las migraciones. El desafío de la inmigración africana en España. Madrid: UNED, pp. 177-187.

Portes, Alejandro y Robert L. Bach (1985) Latin Journey: Cuban and Mexican Immigrants in the United States, Berkeley: University of California Press.

Puerta, Ángel (1987) “Creada una asociación de apoyo a guineanos residentes en España.” Publicado en el periódico ABC el miércoles 7 de enero de 1987, pg. 18.

Rodríguez-García, Dan y Teresa San Román Espinosa (2013) “Inmi- 
gración, salud y gestión de la diversidad: presentación y avances preliminares de un proyecto en barrios de Cataluña." AIBR. Revista de Antropología Iberoamericana, 2(3): 489-520.

Sánchez Molina, Raúl (2011) El pamue imaginado. Madrid: UNED

Sánchez Molina, Raúl (2005) "Mandar a traer.” Antropología, migraciones y transnacionalismo. Madrid: Editorial Universitas.

Sepa Bonaba, Sepa (1993) Els negres catalans. La immigració africana a Catalunya (1993).

Sepa Bonaba, Edmundo (1990). «La Guinea de la Diáspora» Estudios Africanos. No. 8 9, pág. 21-32.

Sipi Mayo, Remei (2004) Inmigración y género. El caso de Guinea Ecuatorial. San Sebastián: Tercera Prensa-Hirugarren Prentsa, S.L.

Sipi Mayo, Remei (1997) "E'Waiso Ipola: Voces del Sur desde el Norte.” DUODA Revista \& d'Estudis Feministes, 13: 157-163.

Vereda Muñoz, Sonia (2003) "Las asociaciones de inmigrantes en España. Práctica clientelar y cooptación política.” Revista Internacional de Sociología (RIS), 36: 207-225.

UNHCR (2001) Equatorial Guinea: The Position of Refugees and Exiles in 2001. Geneva: United Nations High Commissioner for Refugees

Vine, Alex (2009) Well oiled. Oil and Human Rights in Equatorial Guinea. New York: Human Rights Watch.

Wood, Jeoffrey (2004) "Business and politics in a criminal state: the case of Equatorial Guinea.” African Affairs, 103(413): 547-567. 